\title{
An audit of preoperative fasting compliance at a major tertiary referral hospital in Singapore
}

\author{
Hsien Jer $\underline{L i m}^{1}$, MBBS, MMed, Hanjing $\underline{L e e^{2}}$, MBBS, MMed, Lian Kah $\underline{T i}^{1,3}$, MBBS, MMed
}

INTRODUCTION To avoid the risk of pulmonary aspiration, fasting before anaesthesia is important. We postulated that the rate of noncompliance with fasting would be high in patients who were admitted on the day of surgery. Therefore, we surveyed patients in our institution to determine the rate of fasting compliance. We also examined patients' knowledge on preoperative fasting, as well as their perception of and attitudes toward preoperative fasting. METHODS Patients scheduled for 'day surgery' or 'same day admission surgery' under general or regional anaesthesia were surveyed over a four-week period. The patients were asked to answer an eighteen-point questionnaire on demographics, preoperative fasting and attitudes toward fasting.

RESULTS A total of 130 patients were surveyed. 128 patients fasted before surgery, 111 patients knew that they needed to fast for at least six hours before surgery, and 121 patients believed that preoperative fasting was important, with 103 believing that preoperative fasting was necessary to avoid perioperative complications. However, patient understanding was poor, with only $44.6 \%$ of patients knowing the reason for fasting, and $10.8 \%$ of patients thinking that preoperative fasting did not include abstinence from beverages and sweets. When patients who did and did not know the reason for fasting were compared, we did not find any significant differences in age, gender or educational status.

CONCLUSION Despite the patients' poor understanding of the reason for fasting, they were highly compliant with preoperative fasting. This is likely a result of their perception that fasting was important. However, poor understanding of the reason for fasting may lead to unintentional noncompliance.

Keywords: anaesthesia, compliance, fasting, knowledge, preoperative

\section{INTRODUCTION}

All patients who present for surgery under general, regional or monitored anaesthesia are given preoperative fasting instructions. At our institution, adult patients scheduled for surgery before 1:00 pm are required to fast from 12:00 midnight the preceding night, while patients whose surgeries are scheduled to start after 1:00 pm are allowed a light breakfast before 6:00 am. Paediatric patients are required to fast from solid food and milk at least 6 hours before surgery, and from clear fluids at least 2 hours before surgery. Infants are allowed milk up to 4 hours before surgery. In the past, all patients scheduled for elective surgery were admitted to the hospital at least a day before surgery. Fasting rules were strictly enforced by nurses in the wards, and noncompliance was rarely encountered. In recent times, however, patients are increasingly admitted on the day of surgery due to a shortage of hospital beds and economic considerations. As a result, it is our anecdotal observation that there has been an increase in the number of patients who do not comply with fasting instructions. This is despite the fact that all patients are informed of the need to fast before surgery, both verbally and in writing.

Studies in Western countries estimate that approximately $2 \%-3.5 \%$ of patients admitted on the day of surgery are noncompliant with fasting instructions. ${ }^{(1,2)}$ Noncompliance with fasting instructions has resulted in surgeries being delayed or postponed, leading to inconvenience and increasing costs for both the patient and the hospital. More importantly, noncompliance with fasting instructions may compromise patient safety, particularly when patients lie about their fasting times to prevent their surgeries from being delayed or postponed. Laffey et al found that as many as $4 \%$ of their patients would lie about their fasting times if noncompliance meant that their surgery would be delayed or postponed.(1) Reasons proposed for these findings include poor communication between patients and healthcare staff, poor patient understanding, and misinformation.

We therefore embarked on a survey of our patients, who were admitted on the day of surgery, on their knowledge on preoperative fasting, as well as their perception of and attitudes toward preoperative fasting. We aimed to estimate the extent of noncompliance with preoperative fasting instructions in our local patient population and to elicit the reasons for any noncompliance observed.

\section{METHODS}

This study received exemption from review by our institutional review board. The study was conducted over a four-week period, and all patients scheduled for elective 'day surgery' or 'same

${ }^{1}$ Department of Anaesthesia, ${ }^{2}$ Department of Surgery, National University Health System, ${ }^{3}$ Department of Anaesthesia, Yong Loo Lin School of Medicine, National University of Singapore, Singapore

Correspondence: Dr Lim Hsien Jer, Consultant, Department of Anaesthesia, National University Health System, 5 Lower Kent Ridge Road, Singapore 119074. hsienjer@gmail.com 
day admission surgery' under general or regional anaesthesia were eligible to be recruited for the study. Day surgery patients comprise patients who are admitted on the morning of their operation and are expected to be discharged home on the same day. Same day admission surgery patients, on the other hand, are patients who are admitted on the morning of their operation and scheduled to spend at least one night in the hospital postoperatively. In our institution, patients scheduled to receive either general or regional anaesthesia are listed on the daily operating list as general anaesthesia cases. These patients are required to fast before surgery and were eligible for inclusion in the present study. Patients scheduled for either monitored anaesthesia care (MAC) or local anaesthesia were listed as local anaesthesia cases. Although preoperative fasting guidelines apply to patients scheduled to undergo MAC, the guidelines do not apply to patients scheduled to receive only local anaesthesia. As such, to avoid ambiguity, all patients listed as local anaesthesia cases were excluded in the present study. Inpatients were also excluded from the study as nurses typically enforce strict fasting rules in the wards and compliance is rarely a problem. Patients with obtunded sensorium, intellectual impairment and feeding difficulties (e.g. patients on nasoenteral feed) were also excluded.

Eligible patients were approached either at the day surgery ward or the reception area of the main operating theatre complex. The patients were verbally asked by nurses stationed at the patient reception area whether they would be willing to participate in the survey. The nurses involved in the study had been briefed on the objectives of the survey and given detailed explanations on the survey questions. Patients were told that the purpose of the survey was to assess patients' knowledge and views on preoperative fasting, and that the survey would take only 5 mins to complete. They were assured that the survey was confidential and that their answers would not impact their surgeries. Upon agreement, patients were given a survey form to fill in. For children below the age of 16 years, their parents were asked to complete the survey.

The survey form consisted of 18 questions. The first six items documented the demographic data of the patients. The next seven questions pertained to the patients' awareness of the need for preoperative fasting, the personnel who conveyed the fasting instructions to them, and whether they understood the rationale for fasting. The last five questions explored the patients' perception of and attitudes toward the importance of fasting. The survey was available in three languages (i.e. English, Mandarin and Malay), and if required, patients were assisted by two fourthyear medical students. These students were on their elective posting in the Department of Anaesthesia at our institution during the survey period. They had been briefed on the survey and were tasked to assist patients in filling in the survey forms.

Using the survey data, we compared the patients who understood the reason for fasting with those who either did not know the reason they needed to fast or gave an inaccurate reason for fasting. This was done to identify patients who did
Table I. Demographic data of the patients $(n=130)$.

\begin{tabular}{lc}
\hline Variable & No. (\%) \\
\hline Age $^{*}$ (yrs) & $34(1-86)$ \\
Gender & \\
Male & $66(50.8)$ \\
Female & $64(49.2)$ \\
Ethnicity & \\
Chinese & $70(53.8)$ \\
Malay & $21(16.2)$ \\
Indian & $22(16.9)$ \\
Others & $17(13.1)$ \\
Highest education & \\
Tertiary & $55(42.3)$ \\
Secondary & $28(21.5)$ \\
Primary & $25(19.2)$ \\
Nil & $22(16.9)$ \\
\hline *ataispresented as median (range)
\end{tabular}

not know the correct reasons for preoperative fasting and to attempt to understand the reasons behind these patients' lack of knowledge. Data was compiled and analysed using the Statistical Package for the Social Sciences version 19.0 (IBM Corp, Armonk, NY, USA). Continuous data was analysed with unpaired $t$-test, while categorical data was analysed with chi-square test. A p-value of $<0.05$ was taken as significant.

\section{RESULTS}

During the four-week study period, a total of 160 eligible patients were approached to participate in the survey. Of these 160 patients, 130 patients completed the survey. Reasons for non-respondence included patient refusal and language barriers (e.g. foreign patients who could not read any of the survey forms). Of the 130 participating patients, 101 were adult patients and 29 were parents who answered on behalf of their children. None of the 130 patients were obese (defined as having a body mass index of $\geq 27.5 \mathrm{~kg} / \mathrm{m}^{2}$ ). The demographic data of the 130 participating patients are shown in Table I.

Of the 130 patients, 128 patients underwent general anaesthesia, while 2 underwent regional anaesthesia. Only $44.6 \%$ of the patients knew a correct or partially correct reason for the need to fast. These reasons included 'avoid vomiting during surgery', 'requirement of surgery', 'food may obstruct airway' and 'prevent anaesthetic complications'. Almost half $(46.9 \%)$ of the patients did not know the reason for fasting, while another $8.5 \%$ of patients gave an inaccurate reason, such as 'avoid urination and/or bowel movement during surgery', 'prevent surgical complications' and 'avoiding high sugar levels during surgery' (Table II). Overall, 13 (10.8\%) of 120 patients believed that fasting did not apply to beverages or sweets.

All but one of the 130 patients reported that they knew that they needed to fast before surgery. We found that $93.8 \%$ of the patients knew that it was important or very important to fast and $80.5 \%$ believed that fasting was necessary to avoid life-threatening problems. Only two patients admitted to not following the fasting instructions before surgery despite having prior knowledge of its necessity. Four patients, all of whom 
Table II. Patients' knowledge and understanding of preoperative fasting.

\begin{tabular}{|c|c|}
\hline Question & No. (\%) \\
\hline \multicolumn{2}{|l|}{$\begin{array}{l}\text { Have you undergone anaesthesia } \\
\text { or surgery before? }\end{array}$} \\
\hline Yes & $67(51.5)$ \\
\hline No & $63(48.5)$ \\
\hline \multicolumn{2}{|l|}{ Do you know that you need to fast before surgery? } \\
\hline Yes & $129(99.2)$ \\
\hline No & $1(0.8)$ \\
\hline \multicolumn{2}{|l|}{ Who informed you of the need to fast? } \\
\hline Doctor & $18(13.8)$ \\
\hline Nurse & $87(66.9)$ \\
\hline Both the doctor and nurse & $22(16.9)$ \\
\hline Unable to recall & $3(2.3)$ \\
\hline \multirow{2}{*}{\multicolumn{2}{|c|}{$\begin{array}{l}\text { Did you receive written instructions } \\
\text { to fast before surgery? }\end{array}$}} \\
\hline & \\
\hline Yes & $96(73.8)$ \\
\hline No & $34(26.2)$ \\
\hline \multirow{2}{*}{\multicolumn{2}{|c|}{$\begin{array}{l}\text { What is your understanding of the } \\
\text { reason for fasting before surgery? }\end{array}$}} \\
\hline & \\
\hline Avoid vomiting during surgery & $31(23.8)$ \\
\hline Requirement of surgery & $16(12.3)$ \\
\hline Prevent anaesthetic complications & $10(7.7)$ \\
\hline Prevent surgical complications & $7(5.4)$ \\
\hline $\begin{array}{l}\text { Avoid urination and/or bowel movement during } \\
\text { surgery }\end{array}$ & $3(2.3)$ \\
\hline Food may obstruct airway & $1(0.8)$ \\
\hline Avoid high sugar levels during surgery & $1(0.8)$ \\
\hline Don't know & $61(46.9)$ \\
\hline \multicolumn{2}{|l|}{ How long do you need to fast before surgery?* } \\
\hline$<6 \mathrm{hrs}$ & $2(1.6)$ \\
\hline $6-12$ hrs or overnight & $109(85.8)$ \\
\hline$>12 \mathrm{hrs}$ & $2(1.6)$ \\
\hline Don't know & $14(11.0)$ \\
\hline \multicolumn{2}{|l|}{ Does fasting apply to the following foods? ${ }^{+}$} \\
\hline Coffee or tea & $108(90.0)$ \\
\hline Soft drinks & $111(92.5)$ \\
\hline Plain water & $109(90.8)$ \\
\hline Sweets & $111(92.5)$ \\
\hline
\end{tabular}

* 3 patients did not provide an answer to this question. ${ }^{\dagger}$ Data is for patients who answered 'Yes'; 10 patients did not provide an answer to this question.

were adults, answered that while they fasted, they did so for less than the minimum fasting time (i.e. six hours). A total of 14 patients reported fasting excessively (defined as fasting for $>12$ hours) (Table III).

We found no significant difference in the age, gender, ethnicity and educational level between the patients who knew the correct reasons for preoperative fasting and those who did not. Furthermore, it did not make a significant difference in fasting compliance whether the patients were told of the need to fast by doctors, nurses, or both doctors and nurses. Fasting compliance was also observed to not be significantly affected by whether patients had previously undergone a surgery and whether they had received written instructions regarding fasting before surgery (Table IV).

Patients who did not know the correct reason for fasting showed a nonsignificant trend toward poorer understanding of fasting duration and whether fasting applied to coffee, tea, soft drinks, water and sweets. They also tended nonsignificantly toward attaching less importance to compliance with pre-
Table III. Patients' perception of and attitudes toward preoperative fasting.

\begin{tabular}{|c|c|}
\hline Question & No. (\%) \\
\hline \multicolumn{2}{|c|}{$\begin{array}{l}\text { How important do you think it is to comply with } \\
\text { preoperative fasting?* }\end{array}$} \\
\hline Very important & $83(64.3)$ \\
\hline Important & $38(29.5)$ \\
\hline Somewhat important & $7(5.4)$ \\
\hline Not important & $1(0.8)$ \\
\hline \multicolumn{2}{|c|}{$\begin{array}{l}\text { Do you think that following preoperative } \\
\text { fasting instructions is necessary to }\end{array}$} \\
\hline Yes & $103(80.5)$ \\
\hline No & $25(19.5)$ \\
\hline \multicolumn{2}{|c|}{ Did you fast before your surgery today? } \\
\hline Yes & $128(98.5)$ \\
\hline No & $2(1.5)$ \\
\hline \multicolumn{2}{|c|}{ If you fasted, how long did you fast for?+ } \\
\hline$<6 \mathrm{hrs}$ & $4(3.1)$ \\
\hline $6-12 \mathrm{hrs}$ & $110(85.9)$ \\
\hline$>12 \mathrm{hrs}$ & $14(10.9)$ \\
\hline \multicolumn{2}{|c|}{$\begin{array}{l}\text { If you did not follow fasting instructions, } \\
\text { and knew that your surgery will be delayed }\end{array}$} \\
\hline \multicolumn{2}{|c|}{ or postponed because of this, would you lie } \\
\hline \multicolumn{2}{|c|}{ about fasting to your doctors and nurses? } \\
\hline Yes & $22(16.9)$ \\
\hline No & $108(83.1)$ \\
\hline
\end{tabular}

${ }^{\star} 1$ patient did not provide an answer to this question. ${ }^{\dagger} 2$ patients did not provide an answer to these questions.

operative fasting. Of the four patients who fasted for less than six hours, three did not understand the reason for fasting, while one did ( $4.2 \%$ vs. $1.8 \%$; $p=0.628$ ). Similarly, of the 14 patients who fasted for an excessively long time, ten did not know the correct reason for fasting, while four did $(14.1 \%$ vs. $7.0 \%$; $\mathrm{p}=0.260)$.

\section{DISCUSSION}

Preoperative fasting is defined as a prescribed period of time before a procedure during which patients are not allowed oral intake of liquids or solids. ${ }^{(3)}$ Preoperative fasting is an essential component of the strategy to reduce the risk of perioperative pulmonary aspiration. Perioperative pulmonary aspiration is defined as the aspiration of gastric contents into the respiratory system after the induction of anaesthesia (i.e. during a procedure or the immediate period after surgery). Complications due to perioperative pulmonary aspiration may be life-threatening, and include aspiration pneumonia, respiratory disabilities and related morbidities. Preoperative fasting is particularly important as the stress of surgery may delay gastric emptying, and anaesthesia reduces lower oesophageal sphincteric tone and causes the loss of airway reflexes. Apart from fasting, other components of the strategy to reduce the risk of perioperative pulmonary aspiration include the use of pharmacological agents to reduce gastric volume and acidity, and specialised anaesthetic techniques such as rapid sequence induction.

In the present study, we found that our local patients showed good compliance with preoperative fasting instructions. Only $1.5 \%$ of patients admitted to not fasting prior to their 
Table IV. Comparison of the patients who did and did not know the correct reason for preoperative fasting.

\begin{tabular}{|c|c|c|c|}
\hline \multirow[t]{2}{*}{ Variable/Question } & \multicolumn{2}{|c|}{ No. (\%) } & \multirow[t]{2}{*}{ p-value } \\
\hline & $\begin{array}{l}\text { Knew correct } \\
\text { reason }(n=58)\end{array}$ & $\begin{array}{l}\text { Did not know correct } \\
\text { reason }^{\S}(n=72)\end{array}$ & \\
\hline Gender* & & & 0.048 \\
\hline Male & $24(52.2)$ & $22(47.8)$ & \\
\hline Female & $18(32.7)$ & $37(67.3)$ & \\
\hline Age $^{*,+}(y r s)$ & $42.4 \pm 16.6$ & $42.6 \pm 16.9$ & 0.932 \\
\hline Ethnicity & & & 0.561 \\
\hline Chinese & $33(56.9)$ & $37(51.4)$ & \\
\hline Malay & $9(15.5)$ & $12(16.7)$ & \\
\hline Indian & $11(19.0)$ & $11(15.3)$ & \\
\hline Other & $5(8.6)$ & $12(16.7)$ & \\
\hline Highest education* & & & 0.184 \\
\hline Tertiary & $24(43.6)$ & $31(56.4)$ & \\
\hline Secondary & $10(35.7)$ & $18(64.3)$ & \\
\hline Primary & $7(63.6)$ & $4(36.4)$ & \\
\hline $\mathrm{Nil}$ & $1(14.3)$ & $6(85.7)$ & \\
\hline Have you undergone anaesthesia or surgery before?* & $34(58.6)$ & $33(46.5)$ & 0.116 \\
\hline Do you know that you need to fast before surgery?* & $58(100.0)$ & $71(98.6)$ & 0.368 \\
\hline Who informed you of the need to fast? & & & 0.446 \\
\hline Doctor & $7(12.1)$ & $11(15.3)$ & \\
\hline Nurse & $43(74.1)$ & $44(61.1)$ & \\
\hline Both the doctor and nurse & $7(12.1)$ & $15(20.8)$ & \\
\hline Unable to recall & $1(1.7)$ & $2(2.8)$ & \\
\hline Did you receive written instructions to fast before surgery?* & $44(77.2)$ & $52(74.3)$ & 0.836 \\
\hline \multicolumn{4}{|l|}{ Does fasting apply to the following foods?* } \\
\hline Coffee or tea & $51(94.4)$ & $57(86.4)$ & 0.221 \\
\hline Soft drinks & $52(96.3)$ & $59(89.4)$ & 0.183 \\
\hline Plain water & $52(96.3)$ & $57(86.4)$ & 0.109 \\
\hline Sweets & $52(96.3)$ & $59(89.4)$ & 0.183 \\
\hline $\begin{array}{l}\text { How important do you think it is to comply } \\
\text { with preoperative fasting? }\end{array}$ & & & 0.028 \\
\hline Very important & $45(77.6)$ & $38(53.5)$ & \\
\hline Important & $12(20.7)$ & $26(36.6)$ & \\
\hline Somewhat important & $1(1.7)$ & $6(8.5)$ & \\
\hline Not important & $0(0)$ & $1(1.4)$ & \\
\hline $\begin{array}{l}\text { Do you think that following preoperative fasting instructions } \\
\text { is necessary to avoid life-threatening problems?* }\end{array}$ & $45(80.4)$ & $58(80.6)$ & 1.000 \\
\hline Did you fast before your surgery today?* & $57(98.3)$ & $71(98.6)$ & 1.000 \\
\hline If you fasted, how long did you fast for? & & & 0.302 \\
\hline$<6 \mathrm{hrs}$ & $1(1.8)$ & $3(4.2)$ & \\
\hline $6-12 \mathrm{hrs}$ & $52(91.2)$ & $58(81.7)$ & \\
\hline$>12 \mathrm{hrs}$ & $4(7.0)$ & $10(14.1)$ & \\
\hline $\begin{array}{l}\text { If you did not follow fasting instructions, and knew that } \\
\text { your surgery will be delayed or postponed because of this, } \\
\text { would you lie about fasting to your doctors and nurses?* }\end{array}$ & $9(15.5)$ & $13(18.6)$ & 0.815 \\
\hline
\end{tabular}

Figures do not necessarily add up to 130 as not all patients answered every survey question (minimum 120 responses). ${ }^{*}$ Only adult patients $(n=101)$ were considered. ${ }^{\dagger}$ Data is presented as mean \pm standard deviation. ${ }^{\ddagger}$ Data is for participants who answered 'Yes'. ${ }^{\S}$ Includes patients who did not know a reason for preoperative fasting.

surgeries. This compares favourably to patient noncompliance rates reported in other countries $-2 \%, 3.5 \%$ and $3.9 \%$ in surveys conducted in New Zealand, Ireland and Nigeria, respectively. ${ }^{(1,2,4)}$ In our hospital, once patients are scheduled for elective 'day surgery' or 'same day admission surgery', they are given preoperative instructions (including the need to fast) both in verbal and written form by the surgical clinic nurses. Following the requirements of our hospital's standard operating procedure, patients are given an explanation on why they need to fast, as well as the dangers associated with not fasting. Their attending doctors may also brief them on the need to fast, although this was not a requirement. Patients confirmed their understanding of, and their agreement to abide to, the preoperative instructions by signing an acknowledgement form. One working day before their surgery, patients are also reminded via telephone of the need to fast and the risks involved if they do not fast.

The good compliance rate observed in the present study was in line with the positive responses obtained to the questions on attitudes and perception. All patients except one knew that fasting was required, with $93.8 \%$ of the patients stating that fasting was either important or very important 
and $80.5 \%$ thinking it was important because it would help avoid life-threatening complications. Thus, the observed high compliance rate can be explained by the health belief model. The health belief model indicates that patients are more likely to follow physicians' instructions if they believe that: (a) they are susceptible; (b) noncompliance could lead to a problem with serious effects; (c) they have the knowledge that enables them to avoid the problem; and (d) compliance to the instructions will reduce the risk of complications. ${ }^{(5)}$ It is therefore highly likely that the attitudes and perception of our patients contributed significantly to the high compliance rate observed.

A worrying statistic is that almost $17 \%$ of the patients in our study were willing to lie about their fasting status in order to ensure that their surgery proceeded on schedule. This demonstrates a lack of knowledge and understanding of the reason for fasting. Indeed, the patients' understanding of the exact reason why preoperative fasting was needed was poor, with only $44.6 \%$ of our patients giving a correct or partially correct reason. This percentage is much lower than what was found in a survey on local patients performed 14 years ago. ${ }^{(6)}$ In that survey of 132 preoperative patients, Chew et al found that $82.6 \%$ of the patients knew either the correct reason or a partially correct reason for fasting. ${ }^{(6)}$ This large disparity may be partially accounted for by the difference in the survey design free text responses were required in our survey, while multiple choice responses were used in the survey by Chew et al. In our study, we found that our patients fared poorly when compared to a survey from New Zealand.(2) In that survey, although Walker et al found that only $22 \%$ of their patients knew the reason for preoperative fasting, ${ }^{(2)}$ they considered answers that referred to vomiting without mention of aspiration as wrong answers. If Walker et al had considered those answers to be correct, as was done in the present study, the percentage of patients who knew the correct or partially correct reason for needing to fast would be $58 \%{ }^{.2)}$ Although it has been suggested that elderly and male patients are more likely to show a poorer understanding of perioperative instructions, ${ }^{(1)}$ the present study did not find any significant correlation between a poorer understanding of the need for preoperative fasting, and age, gender or any other variable.

Misinformation is another potential cause of poor patient understanding. This is relevant as our institution adopts a very conservative approach to preoperative fasting. Despite the recent publication of updated guidelines from Europe and the United States, which advocate shortening fasting times to as little as two hours for clear fluids and allowing sweets and chewing gum up to the time of surgery, ${ }^{(3,7)}$ our institution's standard operating procedure for preoperative fasting still requires at least six hours of fasting from both liquids and solids. This requirement for at least six hours of fasting is similar in all public hospitals in Singapore. While there is the possibility that doctors may have confused the patients in the present study by advising preoperative fasting based on the recommendations of international guidelines instead of the institution's standard operating procedure, such confusion was not observed.

Given that the patients in the present study were shown to have very good compliance to fasting instructions and were able to attach significant importance to fasting despite a considerable percentage not knowing the reason for fasting, the question arises as to whether having patients understand why they need to fast is necessary at all. From a pragmatic point of view, compliance is far more important than understanding, as this will assure that surgery can proceed safely. Furthermore, the understanding of medical terms and treatments is a challenge for many patients, even without the stress of a scheduled surgery. It is known that stress and anxiety decreases a patient's ability to understand instructions, ${ }^{(8)}$ and that doctors are prone to giving patients information in excess of what they can absorb. ${ }^{(9)}$ Therefore, burdening patients with additional, and possibly unnecessary, information may be detrimental.

Despite this, we believe that understanding is important as the impact of a lack of understanding is two-fold; patients are more likely to, first, be noncompliant, and second, to believe that they were compliant when they were not. In the present study, we found that $77.6 \%$ of the patients who knew a correct reason for fasting perceived fasting to be very important, while only $53.5 \%$ of patients who did not know a correct reason for fasting perceived fasting to be very important. As discussed earlier, attitude drives compliance. It is therefore probable that patients who lack correct understanding are less likely to comply with instructions. Correspondingly, in the study by Walker et al,(2) the authors found that patients who did not understand the reason for fasting were nearly five times more likely to underrate the importance of compliance to fasting. In the present study, patients who lacked understanding were also more likely to be confused as to whether fasting included all liquids and sweets. Between $94.4 \%$ and $96.3 \%$ of patients who knew a correct reason for fasting also knew that they had to avoid all liquids and sweets, while only $86.4 \%$ to $89.4 \%$ of patients who did not know a correct reason knew that fact. This lack of understanding poses a danger as these patients would have believed and reported that they complied with fasting instructions when in actual fact they did not, exposing themselves to the risk of pulmonary aspiration.

In addition, patients who have a poor understanding of the reason for fasting are also more likely to fast excessively. Excessive fasting increases nausea and vomiting, and decreases patient satisfaction. ${ }^{(3)}$ In the present study, $13.9 \%$ of patients who did not know a correct reason for fasting fasted over 12 hours, while only $6.9 \%$ of patients who knew a correct reason made that error. It has also been shown that patients who do not understand the reasons for fasting would be less likely to follow other perioperative instructions, such as the need for continuation or discontinuation of certain medications and the need to arrange for a chaperone to bring them home postoperatively (i.e. the need to abstain from driving post- 
operatively).(1) Therefore, better patient understanding is clearly desirable.

Our institution uses a combination of verbal and written instructions. This is an established combination that is known to be very effective in improving understanding and compliance to perioperative instructions in patients undergoing ambulatory surgery. ${ }^{(10)}$ Although we cannot be completely certain that every clinic nurse followed the standard operating procedure and explained the reasons for fasting to all the patients we surveyed, we are certain that the patients were told the reason for the fasting requirement during their preoperative telephone call reminder, as those calls were made by the same clerk. Adding to patient education using further education techniques (e.g. making patients sit through a video presentation on perioperative instructions) not only entails greater cost and possible patient inconvenience, it also may not improve patient comprehension. ${ }^{(11)}$ Hence, we believe that the key to improving patient understanding is to explain the fasting requirements more clearly. For example, it has been shown that patients who were seen at an anaesthesia preoperative evaluation clinic demonstrated better knowledge of why they needed to fast preoperatively than those who were seen in the ward $(84.0 \%$ vs. $59.0 \% ; \mathrm{p}<0.001)^{(12)}$ Our institution will be increasing the number of anaesthesia preoperative evaluation clinics substantially in the near future, and we believe that this move will result in improved patient understanding of perioperative processes, including the need to fast.

We are cognisant that surveys have inherent limitations, including the fact that patient responses may be subject to personal inhibitions, indifference, honesty and understanding of the issues. However, since this study was relatively nonintrusive and patients were reassured that their responses would not affect their surgeries, we believe that the data obtained from the survey is representative of the general population.

In summary, we found that our local patients were highly compliant with preoperative fasting instructions, likely a result of their perception that fasting was important. Nonetheless, healthcare providers still need to remain vigilant as the general patient's knowledge of the reason for fasting is poor. This lack of knowledge may result in unintentional noncompliance with fasting instructions, leading to an increased risk of pulmonary aspiration.

\section{ACKNOWLEDGEMENT}

We would like to thank our medical students - Mr Joseph Lee Wei En from Yong Loo Lin School of Medicine, Singapore, and Ms Shema Selvadurai from Griffith University, Queensland, Australia - for their help in this study.

\section{REFERENCES}

1. Laffey JG, Carroll M, Donnelly N, Boylan JF. Instructions for ambulatory surgery--patient comprehension and compliance. Ir J Med Sci 1998; 167:160-3.

2. Walker $\mathrm{H}$, Thorn $\mathrm{C}$, Omundsen M. Patients' understanding of pre-operative fasting. Anaesth Intensive Care 2006; 34:358-61.

3. American Society of Anesthesiologists Committee. Practice guidelines for preoperative fasting and the use of pharmacologic agents to reduce the risk of pulmonary aspiration: application to healthy patients undergoing elective procedures: an updated report by the American Society of Anesthesiologists Committee on Standards and Practice Parameters. Anesthesiology 2011; 114:495-511.

4. Adudu OP, Egwakhide EO, Adudu OG. Parents and patients' compliance to revised preoperative fasting guidelines in Benin, Nigeria. Paediatr Anaesth 2008; 18:1013-4.

5. Rosenstock IM, Strecher VJ, Becker MH. Social learning theory and the Health Belief Model. Health Educ Q 1988; 15:175-83.

6. Chew ST, Tan T, Tan SS, Ip-Yam PC. A survey of patients' knowledge of anaesthesia and perioperative care. Singapore Med J 1998; 39:399-402.

7. Smith I, Kranke P, Murat I, et al. Perioperative fasting in adults and children: guidelines from the European Society of Anaesthesiology. Eur J Anaesthesiol 2011; 28:556-69.

8. Harris LM, Cumming SR. An examination of the relationship between anxiety and performance on prospective and retrospective memory tasks. Aust J Psychol 2003; 55:51-5.

9. Sandberg EH, Sharma R, Wiklund R, Sandberg WS. Clinicians consistently exceed a typical person's short term memory during preoperative teaching. Anesth Analg 2008; 107:972-8.

10. Malins AF. Do they do as they are instructed? A review of out-patient anaesthesia. Anaesthesia 1978; 33:832-5.

11. Zvara DA, Mathes DD, Brooker RF, McKinley AC. Video as a patient teaching tool: does it add to the preoperative anesthetic visit? Anesth Analg 1996; 82:1065-8.

12. Schiff JH, Frankenhauser S, Pritsch M, et al. The Anaesthesia Preoperative Evaluation Clinic (APEC): a prospective randomized controlled trial assessing impact on consultation time, direct costs, patient education and satisfaction with anesthesia care. Minerva Anestesiol 2010 $76: 491-9$ 